\title{
Trajetória de crescimento para microempreendedores: diferencial de gênero dos clientes do programa crediamigo
}

\author{
Kamila Vieira de Mendonça \\ Professora - Universidade Federal do Ceará - Instituto de Ciências do Mar (UFC/ Labomar) \\ Endereço: Av. da Abolição, 3207 - Meireles - Fortaleza/CE \\ CEP: 60165-081 - E-mail: kamilavm@gmail.com
}

Ricardo Brito Soares

Professor - Universidade Federal do Ceará (UFC/CAEN)

Endereço: Av. da Universidade, 2700 - Benfica - Fortaleza/CE

CEP: 60020-181-E-mail: ricardosoares@caen.ufc.br

Recebido: 14/08/2014. Aceite 27/10/2015.

\section{Resumo}

Os programas de microcrédito vêm se expandindo em diversos países como alternativa para inserção produtiva dos microempreendedores de baixa renda. Na maioria dos casos, os programas possuem um viés na alocação dos empréstimos em favor das mulheres, assumindo que estas absorvem os compromissos de pagamentos como o fazem com suas responsabilidades familiares e sociais. Desta forma, as mulheres microempreendedoras teriam trajetórias de crescimento mais conservadoras. O objetivo deste trabalho é verificar se existe uma trajetória de crescimento para esse tipo de clientela, e se ela é diferenciada em relação ao gênero. Para isto, estimam-se equações de crescimento para os microempreendimentos dos clientes do Programa Crediamigo para o período de 2005 a 2009. Utilizam-se modelos lineares de efeitos mistos, como proposto por Rabe-Hesketh e Skrondal (2012). Os resultados mostram que existe uma trajetória de crescimento, mas com retornos decrescentes. Adicionalmente, as taxas médias de retorno são um pouco maiores para os homens; porém as mulheres possuem menores riscos em suas trajetórias.

\section{Palavras-Chave}

Microcrédito. Trajetória de Crescimento. Gênero.

\begin{abstract}
Microcredit programs have been expanding in many countries as an alternative to productive insertion of low-income microentrepreneurs. In most cases, programs have a bias in the allocation of loans for women, assuming a greater commitment to these payments, from your best position in the family and society. The objective of this work is to verify whether there is a path of growth for this type of client, and if it is differentiated by gender. In this way, it estimates growth equations for microenterprises of the Crediamigo Program for the period of 2005 to 2009. The equations are estimated by linear mixed effect models, as proposed by Rabe-Hesketh and Skrondal (2012). The results show that there is a growth path, but with diminishing returns. Additionally, average return rates are higher for men; but women have lower risk in their trajectories.
\end{abstract}




\section{Keywords}

Microcredit. Growth trajectory. Genre.

\section{JEL Classification}

D9. G2.

\section{Introdução}

Desde o estabelecimento do Banco Grameen, em Bangladesh, os programas de microcrédito vêm se expandindo em diversos países com diferentes serviços financeiros voltados para a população mais pobre. Segundo Costa (2012), existem mais de 7.000 programas de microcrédito no mundo, com o envolvimento do Terceiro Setor, ${ }^{1}$ bancos públicos e setor privado. Para Banerjee (2013), ${ }^{2}$ a base da expansão do microcrédito tem sido a combinação de taxas de juros mais baixas com o interesse de emprestar para pessoas que não têm acesso ao sistema financeiro formal.

Em face da falta de oportunidades no mercado de trabalho para uma parcela da população, o microcrédito pode ser um poderoso instrumento de política pública de inclusão social. O fornecimento de microcrédito contribui para que a camada menos favorecida da população possa exercer o empreendedorismo de maneira formal, sem recorrer a fontes informais, como familiares e agiotas, para a realização de pequenos investimentos iniciais. Ademais, vários programas de microfinanciamentos preveem acompanhamento e orientação técnica para seus beneficiários, o que favorece o melhor uso dos recursos. Ainda, nestes casos, não é garantido que os microempreendedores sejam bem sucedidos continuamente, visto que precisam, além de pagar por seus empréstimos, gerar retornos para os seus micronegócios e para as suas famílias.

Os desafios podem ser ainda maiores para as mulheres microempreendedoras, na medida em que se somam a esse conjunto de obrigações do trabalho as tarefas domésticas, geralmente assumidas por estas, e que demandam uma alocação de tempo considerável. No entanto, vários programas de microfinanciamentos possuem orientações distributivas voltadas para as mulheres, seja por

1 O Terceiro Setor é formado em sua maioria por Organizações da Sociedade Civil de Interesse Público de microcrédito e Sociedades de Crédito ao Microempreendedor.

2 Os autores agradecem a contribuição dos pareceristas da revista Estudos Econômicos. 
orientações de política social (redução de discriminação e melhora do empoderamento) ou porque apostam que o compromisso com o empréstimo mimetiza o compromisso familiar. Nesse sentido, as mulheres empreendedoras podem ser mais aversas ao risco que os homens, preferindo endividamentos conservadores, que possuem maiores chances de pagamento. Esta última característica é importante para os programas de microcrédito, cuja sustentabilidade depende exatamente do compromisso do cliente com o programa ao longo de sua permanência.

Diferenciais de desempenho por gênero para microempreendedores são encontrados em vários aspectos na literatura econômica. Croson e Gneezy (2009) realizam uma extensa revisão da literatura, enfatizando o papel da aversão ao risco como fator importante na explicação desses diferenciais. Os autores observaram que em geral mulheres são mais aversas ao risco tanto no mercado de trabalho, como no mercado de bens e serviços. Fossen (2009) verifica que uma boa parcela do diferencial de empreendedorismo a favor dos homens, na Alemanha, está relacionada à aversão ao risco. Acerca do retorno de crescimento de microempreendimentos, Matlary (2013) encontra resultados desfavoráveis para as mulheres, não estabelecendo, no entanto, uma relação de causa e efeito.

No Brasil, poucos estudos empíricos tratam da questão de crescimento do microempreendedor em geral ou do diferencial de desempenho que pode haver com respeito ao gênero. Monzoni Neto (2006), analisando o impacto na geração de renda do programa de crédito solidário "São Paulo Confia", verificou tanto a existência de impacto geral no lucro do microempreendimento, quanto um diferencial de retorno do crédito desfavorável às mulheres. Barreto et al. (2010) analisaram a saída da pobreza de clientes do programa Crediamigo e verificaram também que as mulheres possuem uma probabilidade comparativamente menor de sair desta situação.

Seguindo outra linha, diversos estudos apontam que não existem dados concretos a respeito dos efeitos do microcrédito. Apesar da expansão dos programas, em estudos feitos na Etiópia, Índia, México e Marrocos ainda é baixa a demanda por microcrédito. Além disso, existem poucas evidências de que o acesso ao microcrédito teve efeitos substanciais sobre o empoderamento das mulheres (ABDUL LATIF JAMEEL POVERTY ACTION LAB, 2015). 
Este trabalho procura estimar as equações de crescimento para o lucro operacional dos microempreendimentos dos clientes do Programa Crediamigo. Para isto, utiliza uma base de dados em painel com informações anuais para o período de 2005 a 2009, e modelos lineares de efeitos mistos para intercepto e coeficiente conforme proposto por Rabe-Hesketh e Skrondal (2012).

O Crediamigo é o maior programa de microcrédito produtivo orientado da América do Sul que fornece crédito a empreendedores pertencentes aos setores formal e informal da economia. A concessão de crédito ocorre de maneira rápida e com pouca burocracia em grupo solidário ou individual. Além do crédito, são oferecidos aos empreendedores acompanhamento e orientação para aplicação do recurso via agentes de crédito, que fidelizam os clientes e incentivam suas renovações (BNB, 2013). Isto permite que vários microempreendedores fiquem no programa por um bom período de tempo, podendo formar assim uma trajetória evolutiva do seu negócio.

Além desta introdução, o trabalho está organizado em mais quatro seções. Na segunda seção tem-se a revisão de literatura sobre microcrédito, destacando-se pesquisas de desempenho dos clientes de programas de microcrédito por gênero. A terceira apresenta a descrição da metodologia, da base de dados e das variáveis utilizadas nos modelos de crescimento, e a quarta analisa os resultados econométricos em que se pretende verificar como sucessivas tomadas de crédito estão associadas com o aumento (ou não) do lucro operacional dos microempreendimentos. Na busca dessa relação, testa-se e investiga-se diferenciais de performance entre homens e mulheres clientes do programa, além de outras características que podem condicionar maiores retornos dos micronegócios. Finalmente, procura-se considerar como os resultados refutam ou não a hipótese de trajetórias diferenciais de crescimento por gênero, e como os mesmos podem ser utilizados para uma melhor gestão do programa, ou mesmo, para guiar políticas de inserção social. 


\section{Revisão de literatura}

O microcrédito é um modelo de concessão de crédito para pessoas que não possuem acesso ao crédito padrão e não fazem parte do mercado formal por não possuírem as condições exigidas pelos bancos. Essas exigências, por constituírem uma falha de mercado, ${ }^{3}$ levaram à implementação do microcrédito como alternativa de redução dos problemas gerados pelas restrições do crédito tradicional.

Considerando as diferenças entre os microempreendedores, diversos autores procuram investigar as variáveis que influenciam o desempenho destes. Fontes e Pero (2013) examinaram empiricamente os determinantes da desigualdade e dos rendimentos dos microempreendedores com base nos dados da Pesquisa da Economia Informal e Urbana $^{4}$ e verificaram que o capital humano (medido por meio do nível de escolaridade) e o capital financeiro são essenciais para as atividades desenvolvidas pelos microempresários.

Uma investigação empírica do impacto do microcrédito sobre a renda foi feita por Monzoni Neto (2006). O autor verificou que este impacto na geração de renda é significativo, sinalizando que o acesso ao fator capital para a produção viabilizado via crédito proporcionou um novo patamar de renda para as famílias beneficiadas. Outros pesquisadores também analisam o impacto do microcrédito para além do simples retorno de lucro do negócio. Carreño et al. (2013), por exemplo, verificaram que as famílias com acesso ao microcrédito na Colômbia possuem mais ativos não financeiros, sumarizados pelo índice de ativos dos lares, que são considerados na pesquisa como medidas de bem-estar.

Uma vasta literatura também foi produzida acerca dos vários aspectos de gênero dos programas de microcrédito. Entre os aspectos investigados têm-se a relação entre a participação no programa de microcrédito e a concepção de empoderamento das mulheres, além dos efeitos diferenciados de retorno e renda das mesmas por conta de suas atitudes, como por exemplo, a maior preocupação com a saúde, a alimentação, as crianças e a família.

3 As falhas de mercado são motivadas por fatores como informação incompleta, elevados custos de transação e existência de externalidades.

4 A Pesquisa da Economia Informal e Urbana foi realizada em 1997 e 2003 e apresenta a situação dos pequenos empreendimentos não agrícolas, em especial do setor informal, abrangendo informações dos negócios e características das pessoas ocupadas. 
Em Portugal, a importância do microcrédito por gênero foi pesquisada por Fernandes (2013). Nesse estudo, o autor encontrou que o microcrédito é concedido majoritariamente a mulheres, que o grau de exclusão é maior para os homens, e que estes se tornam mais dependentes em relação ao crédito na condução de seus negócios.

O microcrédito pode aumentar o poder de barganha das mulheres na família, que passam a ter um novo papel no controle das finanças e, consequentemente, maior autonomia no lar. Pitt e Khandker (1998) estimaram o impacto da participação, por gênero, no Banco Grameen e em outros dois programas de microcrédito em Bangladesh, baseados na oferta de trabalho, escolaridade, despesas da família e ativos. Os autores encontraram que o programa de crédito tem um efeito maior sobre o comportamento das famílias pobres quando as mulheres participam do programa. Ao obter microcrédito, elas têm a oportunidade de se tornarem independentes e ativas na economia, pois podem, com isso, aumentar, controlar e adquirir bens. Righetti (2012), ao investigar o impacto do microcrédito produtivo de um banco comercial, também observou um maior aumento na renda para as mulheres participantes do programa.

Para Duflo (2011), as mulheres têm maior propensão a gastar a renda em bens socialmente benéficos como serviços de saúde e alimentação. Dessa forma, os retornos do capital para as mulheres são maiores que os dos homens em termos de desenvolvimento econômico. Sen (2000) demonstra que o ganho de poder das mulheres na família pode reduzir a mortalidade infantil e, associado à educação e ao emprego, elas podem influenciar a natureza das discussões públicas a respeito de diversos temas sociais. Ter emprego remunerado produz efeitos positivos principalmente nos cuidados com os filhos, pois usualmente é das mulheres a maior responsabilidade por estes. Este efeito foi proporcionado com êxito pelo Banco Grameen, com seu esforço para fornecer microcrédito a mulheres.

Conforme Yunus (1999), antes da criação do Banco Grameen, os empréstimos concedidos às mulheres eram de menos de $1 \%$. Ao converter seu projeto em um banco formal, Yunus pretendia oferecer crédito aos mais pobres, pois, para ele, a pobreza é originada pelas instituições e políticas de exclusão criadas em uma sociedade em que não se dão oportunidades, principalmente às mulheres. Atualmente, 
o banco concentra a sua ação, que se revelou uma arma eficaz contra a pobreza, nas mulheres miseráveis.

As mulheres também devem ser contempladas no campo do microcrédito por constituírem influência indispensável no desenvolvimento de suas comunidades (Cheston, 2006). Sua participação em programas de microcrédito ajuda a aumentar o empoderamento na tomada de decisão familiar, facilita o acesso a financiamentos e recursos econômicos, favorece o relacionamento em redes sociais, amplia o poder de barganha e dá maior mobilidade. Também influencia favoravelmente na comunicação conjugal, notadamente acerca do planejamento familiar (Pitt et al., 2003).

Com relação ao crescimento e retorno dos microempreendimentos, o diferencial de gênero é explicado em grande parte pela teoria do risco. Croson e Gneezy (2009) enfatizam que existem diferenças nas preferências pelo risco que estão relacionadas a fatores emocionais: excesso de confiança, e risco como desafio ou ameaça. Enquanto para os homens o risco é visto como um desafio que exige maior participação, para as mulheres seria uma ameaça. Para os autores, uma experiência emocional mais forte pode afetar a utilidade de escolha do risco, e as mulheres, em situações deste tipo, são mais nervosas e temerosas que os homens. Quanto ao excesso de confiança, ambos possuem esta característica, porém os homens são mais confiantes do que as mulheres em situações de incerteza. Ainda segundo tais autores, as mulheres são mais confiáveis do que os homens e essa diferença deve-se à maior sensibilidade das mulheres às sugestões da sociedade na determinação do comportamento apropriado.

Para Neri (2008), as mulheres são as verdadeiras protagonistas econômicas dos negócios familiares. Ainda segundo o autor, apesar destas obterem lucro operacional inferior ao dos homens, o retorno obtido por elas é superior, pois o microcrédito, em geral, funciona como fonte de financiamento da revolução feminina. Isso pode ser consequência da participação das mulheres nas diversas atividades sociais, econômicas e culturais relacionadas ao desenvolvimento.

Badunenko et al. (2009) realizaram pesquisa em domicílios de cinco países europeus. Os autores encontraram diferenças de gênero, demonstrando que as mulheres são menos propensas a investir em ativos de risco. Segundo Mel et al. (2007), como os homens têm maior 
influência sobre a destinação da renda no agregado familiar, podem, em parte, determinar as decisões de investimento das mulheres, mas a razão pela qual as mulheres deixam de investir permanece desconhecida. Recentes estudos feitos por Bönte e Jarosch (2011) relatam que as diferenças entre homens e mulheres na aversão ao risco devem-se à forma de socialização das mulheres e à falta de encorajamento para competir em um ambiente de negócios. Ainda no que se refere à influência do fator gênero no sucesso do negócio, Schör (2006) constatou que a maioria dos empreendedores são homens, que estes dominam fortemente o processo de inovação e a parte técnica, são ligeiramente mais objetivos que as mulheres e consideram a taxa de rentabilidade boa, o que os torna mais otimistas.

Consoante Aghion e Morduch (2005), a mulher é mais conservadora em suas estratégias de investimento, fato este que também será investigado no presente trabalho. Apesar dos ganhos de poder das mulheres advindos do microcrédito, não há consenso sobre o papel do gênero no comportamento diante do investimento. Seguindo a hipótese de diferenciação nas preferências pelo risco, espera-se que as mulheres tenham trajetórias de crescimento com menores retornos, acompanhados de menores riscos. Esta hipótese será testada por meio da estimação de equações de crescimento em modelos de efeito misto.

\section{Metodologia}

\subsection{Modelos lineares de efeitos mistos}

A metodologia utilizada para estimar equações de crescimento neste estudo é baseada na análise de dados em painel, que permite a exploração simultânea de variações das variáveis ao longo do tempo e entre indivíduos. Essa técnica de junção dos dados temporais e seccionais permite uma estimação mais completa e mais eficiente do modelo (Wooldridge, 2002).

Porém, devido à heterogeneidade entre os indivíduos, a estimação dos modelos em painel torna-se mais complicada. Sendo assim, dados longitudinais requerem métodos especiais de análise, porque as respostas do mesmo indivíduo em momentos diferentes não devem 
ser independentes. Para um modelo de regressão linear, isso significa que os resíduos para o mesmo indivíduo estão de alguma forma correlacionados. Podemos modelar essas correlações residuais por partição do resíduo total do indivíduo $i$ no tempo $j$ em um intercepto aleatório ou em um componente permanente que é constante ao longo do tempo, além de um resíduo que varia aleatoriamente no período.

Para isso, utilizamos o modelo linear misto, também conhecido como análise multinível, modelo hierárquico linear, modelo de efeitos aleatórios ou regressão hierárquica. A análise do crescimento individual é uma extensão do modelo de regressão tradicional em que as variáveis analisadas são dispostas em diversos níveis de agregação. Ou seja, o indivíduo é o primeiro foco da análise, a partir do qual é possível verificar níveis superiores em uma hierarquia (Rabe-Hesketh e Everitt, 2006).

Segundo Bryk e Raudenbush (1986), o modelo hierárquico linear tem ampla utilização na pesquisa social e psicológica, como, por exemplo, em estudos de crescimento individual na própria altura (curva de crescimento das crianças) ou em medidas de desempenho (notas dos alunos ao longo das séries).

De acordo com Fávero et al. (2009), o uso desses modelos permite considerar as diferenças contextuais, levando-se em conta que as observações e os contextos são diferentes em cada caso, e permite, também, analisar de forma simultânea contextos e heterogeneidades individuais. Sendo assim, enquanto uma hipótese possível se refere ao conjunto de indivíduos, outras hipóteses trabalham no nível entre indivíduos, buscando explicação na diferença entre eles. Isso ocorre no contexto dos clientes do Crediamigo, em que se deseja estudar o desempenho do empreendedor com base nas variáveis associadas ao próprio microempresário e variáveis associadas ao microempreendimento. Ao tratar variáveis em diferentes níveis, o modelo de regressão tradicional não leva em consideração a correlação entre indivíduos associados a um mesmo nível de agregação. Já métodos que utilizam a curva de crescimento fornecem uma forma eficiente de representar a dependência causada pelo fato de que os mesmos indivíduos foram avaliados repetidamente. 
Os modelos lineares de efeitos mistos ${ }^{5}$ podem ser representados em notação matricial da seguinte forma:

$$
Y=X \beta+Z u+\varepsilon
$$

Onde $Y$ é um vetor de desempenho $n \times 1, X$ é uma matriz de covariáveis $n \times p$ para os efeitos fixos, $\beta$; e $Z$ é uma matriz de covariáveis para os efeitos aleatórios, ${ }^{6} \boldsymbol{u}$. Por hipótese, o vetor de erros $n \times 1, \mathcal{E}$, tem distribuição normal multivariada com média zero e matriz de variância $\sigma_{\varepsilon}^{2} R$.

A parte fixa em (1), $X \beta$, é semelhante ao preditor linear do modelo de regressão linear padrão, com os coeficientes de regressão estimados, $\beta$. Para a parte aleatória de (1), $Z u+\varepsilon$, assume-se que $\boldsymbol{u}$ tem matriz de variância-covariância $G$ e que $\boldsymbol{u}$ é ortogonal a $\boldsymbol{\varepsilon}$, de modo que:

$$
\operatorname{Var}\left[\begin{array}{l}
u \\
\varepsilon
\end{array}\right]=\left[\begin{array}{cc}
G & 0 \\
0 & \sigma_{\varepsilon}^{2} R
\end{array}\right]
$$

Os efeitos aleatórios, $\boldsymbol{u}$, não são diretamente estimados, mas são caracterizados pelos elementos de $G$, conhecidos como componentes de variância, que são estimados com a variância residual global $\sigma_{\varepsilon}^{2}$ e os parâmetros da variância residual que estão contidos em $R$.

A forma geral das matrizes $X$ e $G$ permite estimar diversos modelos lineares - modelos em blocos, curvas de crescimento, modelos hierárquicos - além de permitir um método flexível de modelar a correlação dentro do grupo. Em nível do indivíduo, o mesmo grupo pode estar correlacionado com o resultado do intercepto aleatório compartilhado, ou por meio da inclinação aleatória compartilhada da idade, por exemplo, ou em ambos. Este é o caso mais comum na estimação de curvas de crescimento que é a especificação oferecida e testada neste trabalho da seguinte forma: ${ }^{7}$

$$
y_{i j}=\beta_{1}+\beta_{2} x_{i j}+\beta_{3} x_{i j}^{2}+u_{0 i}+u_{1 i} x_{i j}+\varepsilon_{i j}
$$

\footnotetext{
5 Ver StataCorp (2011).

${ }^{6}$ Geralmente um subconjunto de X.

7 Esta exposição do modelo está baseada em West, Welck e Galecki (2009). Por simplificação, não incluímos outras covariáveis no modelo. Também vale adiantar que a especificação com termo aleatório para o tempo ao quadrado não se mostrou significante na estimação empírica.
} 
Onde $y_{i j}$ é o lucro operacional do microempreendedor $i$ no período $j, x_{i j}$ corresponde ao tempo de programa do mesmo, e $x^{2}{ }_{i j}$ é o valor ao quadrado do tempo de programa que procura capturar trajetórias não lineares de crescimento. Os parâmetros $\beta_{1}, \beta_{2}$, e $\beta_{3}$ representam os efeitos fixos associados com o intercepto e com as variáveis de tempo (linear e quadrática). O parâmetro $\beta_{2}$ é de grande importância neste trabalho, uma vez que representa a variação no lucro operacional por unidade de tempo, sendo assim o próprio indicador de retorno do programa.

No modelo de coeficiente aleatório, podemos ainda usar a formulação hierárquica. O modelo no nível l é descrito como:

$$
y_{i j}=\eta_{0 i}+\eta_{1 i} x_{i j}+\beta_{3} x_{i j}^{2}+\varepsilon_{i j}
$$

Onde o intercepto $\eta_{0 i}$ e a inclinação $\eta_{1 i}$ são coeficientes dos microempresários específicos. O modelo no nível 2 tem os seguintes coeficientes como respostas:

$$
\begin{aligned}
& \eta_{0 i}=\gamma_{11}+u_{0 i} \\
& \eta_{1 i}=\gamma_{21}+u_{1 i}
\end{aligned}
$$

Substituindo o modelo do nível 2 no nível 1, obtemos a forma reduzida:

$$
\begin{aligned}
& y_{i j}=\gamma_{11}+u_{0 i}+\left(\gamma_{21}+u_{1 i}\right) x_{i j}+\beta_{3} x_{i j}^{2}+\varepsilon_{i j} \\
& y_{i j}=\gamma_{11}+\gamma_{21} x_{i j}+\beta_{3} x_{i j}^{2}+u_{0 i}+u_{1 i} x_{i j}+\varepsilon_{i j} \\
& y_{i j} \equiv \beta_{1}+\beta_{2} x_{i j}+\beta_{3} x_{i j}^{2}+u_{0 i}+u_{1 i} x_{i j}+\varepsilon_{i j}
\end{aligned}
$$

Onde $\beta_{1} \equiv \gamma_{1}$ e $\beta_{2} \equiv \gamma_{21}$

Os termos $\mathrm{u}_{0 i}$ e $\mathrm{u}_{1 i}$ nas equações anteriores representam os efeitos aleatórios associados com o intercepto específico do microempreendedor e do efeito linear do tempo de programa. A distribuição do vetor de efeitos aleatórios $u_{\mathrm{i}}$ associada com o microempreendedor $i$ é assumida ser normal multivariada da seguinte forma:

$$
u_{i}=\left(\begin{array}{l}
u_{0 i} \\
u_{1 i}
\end{array}\right) \sim N(0, G)
$$


Cada um dos efeitos aleatórios possui média zero, e a matriz de variância e covariância $G$ dos mesmos é dada por:

$$
G=\left(\begin{array}{cc}
\sigma_{\text {intercepto }}^{2} & \sigma_{\text {interc,tempo }} \\
\sigma_{\text {interc,tempo }} & \sigma_{\text {tempo }}^{2}
\end{array}\right)
$$

Neste caso, não estamos impondo nenhuma estrutura fixa nesta matriz, que poderia ser modelada alternativamente com variâncias iguais ou independentes. ${ }^{8}$ A variância correlacionada ao tempo de programa ao nível do indivíduo, $\sigma_{\text {tempo }}^{2}$ captura a variabilidade do retorno, sendo portanto uma aproximação para o risco da trajetória de crescimento do microempreendedor.

O termo $\varepsilon_{i j}$ na Equação 3 é o erro residual para o microempreendedor $i$ no período $t$, cuja distribuição é normal com média zero e variância fixa.

$$
\varepsilon_{i j} \sim N\left(0, \sigma^{2}\right)
$$

Assume-se ainda que os resíduos são independentes e identicamente distribuídos, condicionados aos efeitos aleatórios, e que não existe correlação entre estes. O ponto central para ajustar modelos mistos está na estimação dos componentes de variância, e, para isso, existem muitos métodos. Os mais comuns são o de máxima verossimilhança (ML) e o de máxima verossimilhança restrita (REML). As estimativas por ML são baseadas na aplicação usual da teoria de verossimilhança. A ideia básica do REML é que é possível formar um conjunto linear de resposta que não depende dos efeitos fixos, $\beta$, mas, em vez disso, depende dos componentes de variância. Em seguida, aplica-se o método ML para formar a verossimilhança. Uma vantagem da estimação por ML é que o mesmo permite comparar modelos via teste de razão de verossimilhança quando os mesmos possuem diferentes especificações (número) de efeitos fixos. O teste para verificar a significância do efeito fixo do tempo ao quadrado, e, portanto, do modelo quadrático por exemplo, só pode ser realizado pelo método ML. Desta forma, este método será utilizado para a

8 A opção por uma matriz de variância e covariância não estruturada ocorreu não apenas por esta prover melhor ajuste para o modelo, como pelo efeito significante da correlação dos termos aleatórios (Rabe-Hesketh e Skrondal, 2012). 
estimação da curva de crescimento do lucro operacional dos clientes do programa Crediamigo. ${ }^{9}$

Em favor da hipótese que as mulheres são mais conservadoras em suas trajetórias de crescimento, espera-se uma variância menor para as taxas de retornos, que podem ser também menores para estas. Em termos de parâmetros, espera-se que $\beta_{2}$ seja maior para os homens, e $\sigma_{\text {tempo }}^{2}$ seja menor para as mulheres. Adicionalmente, também podemos observar como diferentes covariáveis afetam o lucro operacional dos microempreendedores estimando equações diferenciadas por gênero, e por faixa de lucro quando entram no programa.

\subsection{Base de dados e descrição das variáveis}

Lançado em 1998, o programa de microcrédito do Banco do Nordeste (BNB), conhecido como Crediamigo, atua na região Nordeste e no Norte dos Estados de Minas Gerais e Espírito Santo, abrangendo 1.420 municípios (Neri, 2008). A partir de 2009, o Banco também passou a atuar no Rio de Janeiro.

O Crediamigo é o Programa de Microcrédito Produtivo Orientado que facilita o acesso ao crédito a empreendedores, formais ou informais, que desenvolvem atividades relacionadas à produção, comercialização e prestação de serviços. A diferença em relação ao sistema tradicional de financiamento é que o cliente não precisa necessariamente ir até o banco para fazer o empréstimo, ou seja, os agentes de crédito vão aos clientes no próprio local de trabalho, onde fazem a análise socioeconômica. Tal procedimento representa, também, redução nos custos de transação e de oportunidade. ${ }^{10}$

Além do crédito, são fornecidos aos empreendedores acompanhamento, orientação e acesso ao sistema bancário, para tornar eficiente a aplicação do recurso e, com isso, integrá-los de maneira competitiva ao mercado (BNB, 2013). O perfil dos clientes é basicamente forma-

9 Adicionalmente, os parâmetros tendem a convergir nos dois métodos quando a amostra é muito grande, sendo este o caso presente. Ou seja, o modelo estimado por REML não apresentou diferenças em significância e direção dos parâmetros, apresentando ainda diferenças mínimas em suas magnitudes.

${ }^{10}$ Os custos de transação ocorrem no processo de liberação do crédito, como o custo de deslocamento até a instituição, o custo da documentação, dos saques, entre outros. O custo de oportunidade refere-se ao tempo gasto para levantamento da documentação e ida à agência bancária. 
do por pessoas que trabalham por conta própria, de modo individual ou em grupo, e atuam nos setores formal ou informal da indústria, comércio ou serviços.

O funcionamento do programa ocorre de forma rápida e com pouca burocracia, devido ao método do aval solidário, que tem como característica a união de um grupo solidário de empreendedores interessados em obter crédito, assumindo a responsabilidade no pagamento das prestações. Sendo assim, é possível a obtenção do crédito por parte de pessoas menos favorecidas economicamente, para quem a oferta de garantias é de difícil alcance. Essa metodologia consolidou tal programa como o maior do país no que se refere ao microcrédito produtivo orientado, garantindo o fortalecimento das atividades de milhares de empreendedores e proporcionando a melhoria da qualidade de vida de grande parte da população.

No ano de 2002, a quantidade de operações foi de aproximadamente 360 mil, tendo atingido mais de 2 milhões e 800 mil em 2012. $\mathrm{O}$ crescimento nos valores desembolsados também foi expressivo nesse período, passando de $\mathrm{R} \$ 287,3$ milhões para $\mathrm{R} \$ 4.320,1 \mathrm{mi}$ 1hões. O número de clientes ativos, que, em 2002, perfazia cerca de 119 mil, passou para mais de 1 milhão em 2012. Em maio de 2013, $65 \%$ dos clientes eram formados por mulheres. O Estado do Ceará apresentou o maior número de contratações (cerca de 1 milhão de empréstimos) no acumulado do período de 1998-2011, seguido da Bahia e Maranhão (BNB, 2013). Esse aumento no número de operações pode estar relacionado à criação de empresas. Segundo Schör (2006), vários fatores são determinantes para que os homens e as mulheres criem sua própria empresa, dentre eles, a expectativa de gerar riqueza e o desejo de novos desafios. No caso das mulheres, a motivação seria evitar o desemprego e poder combinar a vida privada com a vida profissional.

O programa de microcrédito Crediamigo possui uma base de dados de acompanhamento com informações anuais sobre clientes ativos, com pelo menos dois fluxos de informações: um deles gerado na entrada no programa, que é dado pela condição inicial, e outro referente à posição final, dado pelo último registro do ano. Para este trabalho foram selecionados os clientes com primeiro fluxo em 2005 
e que permaneceram no programa até o último fluxo em 2009, constituindo, assim, um painel equilibrado. ${ }^{11}$

\section{As variáveis utilizadas no modelo são descritas na Tabela 1 .}

\section{Tabela 1 - Descrição das Variáveis}

\begin{tabular}{|c|c|}
\hline CATEGORIA & CARACTERÍSTICAS/TIPO \\
\hline Tempo de Programa & $\begin{array}{l}\text { Tempo de Programa - Período de inclusão no programa contabilizado a partir da } \\
\text { data de entrada (primeiro fluxo). }\end{array}$ \\
\hline & Lucro Operacional - Renda do empreendedor (valor de retirada do negócio). \\
\hline Renda & $\begin{array}{l}\text { Outras Rendas - Renda do cliente que não é proveniente do negócio (transferên- } \\
\text { cias governamentais, por exemplo). }\end{array}$ \\
\hline \multirow{5}{*}{ Indivíduo e Família } & Idade - Idade, em anos, ao entrar no programa. \\
\hline & $\begin{array}{l}\text { Nível Educacional - Condição educacional ao entrar no programa: analfabeto, } \\
\text { primeiro grau (ensino fundamental) incompleto, primeiro grau completo, segundo } \\
\text { grau (ensino médio) ou terceiro grau (superior) completo. }\end{array}$ \\
\hline & Gênero -Variável binária: 1 = Homem, 0 = Mulher. \\
\hline & Tipo de Domicílio - Próprio, alugado, emprestado, de familiares ou não informado. \\
\hline & UF - Unidade da Federação a qual pertence o empreendedor. \\
\hline \multirow{7}{*}{ Empresa } & Característica do Negócio - Variável dicotômica: 1 = Ambulante, 0 = Fixo. \\
\hline & $\begin{array}{l}\text { Estrutura Física do Negócio - Variável categórica: casa, barraca, ponto fixo, ser- } \\
\text { viço em domicílio e móvel. }\end{array}$ \\
\hline & $\begin{array}{l}\text { Tempo de Atividade - Quanto tempo o cliente tem de experiência na atividade } \\
\text { (informada pelo mesmo), em anos. }\end{array}$ \\
\hline & Setor de Atividade - Comércio, indústria ou serviço. \\
\hline & $\begin{array}{l}\text { Tipo de Controle Administrativo - Variável categórica construída de acordo com } \\
\text { a classificação do Assessor de Crédito em visita ao negócio: bom, satisfatório, } \\
\text { precário e inexistente. }\end{array}$ \\
\hline & $\begin{array}{l}\text { Prazo de Venda do Cliente - } 0 \text { cliente pode responder que vende somente à vista, } \\
\text { ou com prazos variando de } 1 \text { a } 3 \text { meses. }\end{array}$ \\
\hline & Quantidade de Operações no período. \\
\hline \multirow{3}{*}{ Empréstimo } & $\begin{array}{l}\text { Valor do Empréstimo ou Financiamento - Valor individual que o cliente recebeu de } \\
\text { crédito quando iniciou no programa. }\end{array}$ \\
\hline & Prazo do empréstimo ou financiamento - Prazo em meses do empréstimo. \\
\hline & $\begin{array}{l}\text { Participação no empréstimo - Participação percentual do empréstimo individual no } \\
\text { montante do grupo solidário. }\end{array}$ \\
\hline
\end{tabular}

Fonte: Adaptado de Barreto et al. (2010).

${ }^{11}$ Um painel equilibrado ou balanceado possui todas as observações, ou seja, as variáveis são observadas para cada unidade em cada período de tempo. 
A variável denominada Tempo de Programa procura demonstrar a dinâmica dos clientes com relação à condição econômica. Além disso, essa variável capta a eficácia do programa de acompanhamento do Crediamigo, considerando o efeito do apoio técnico personalizado dos agentes de crédito sobre os clientes mais vulneráveis (Barreto et al., 2010).

Optou-se pela adoção do lucro operacional como variável dependente de resultado que, segundo Neri (2008), corresponde à renda do trabalho disponível para ser alocada entre consumo e investimento. Por isso, reflete o desempenho do microempreendimento, considerando-se a precisão da coleta dos dados. Os dados de lucro operacional caracterizam-se como hierárquicos e de medidas repetidas, ou seja, o valor dessa variável é mensurado para um mesmo cliente em diferentes momentos (anos). Os valores do lucro operacional e dos empréstimos foram deflacionados com base no Índice de Preços ao Consumidor (IPC) de dezembro de 2009.

\subsection{Análise descritiva da base de dados}

A amostra final deste trabalho foi formada a partir dos clientes que entraram no programa em 2005, e que possuíam informações de dois fluxos neste ano, totalizando 36.834 clientes. Destes, apenas $9.470^{12}$ continuaram ativos no programa até 2009, tinham idade acima de 18 anos e possuíam informações válidas para as variáveis-chave do modelo. Essa perda de registros ao longo dos anos pode gerar um viés de seleção, dado que a saída do programa pode estar correlacionada com seu desempenho. Desta forma, é preciso cautela na generalização dos resultados das trajetórias.

Para a análise comparativa entre homens e mulheres, se a perda de registros for proporcional, este viés de seleção é diminuído. As amostras iniciais e finais de clientes que entraram em 2005 mostram um percentual de mulheres de $62,7 \%$ e $65,9 \%$, respectivamente, o que indica que a saída dos homens do programa é apenas um pouco maior.

$\overline{12}$ Ver estatísticas descritivas no Apêndice A. 
Das características dos microempreendedores que permaneceram cinco anos no programa, observou-se que, ao entrar no programa, a idade média dos homens é de 40 anos e das mulheres de 38 anos. A maioria feminina, $66 \%$, pode, em parte, decorrer da necessidade de as mulheres exercerem atividades nas quais possam conciliar o trabalho com os afazeres do lar, ao contrário dos homens, que buscam certa segurança no trabalho com carteira assinada. A partir desses resultados, percebe-se que as mulheres estão se destacando como empreendedoras, além de complementar a renda familiar.

O grau de instrução com maior frequência é dado pelo primeiro grau incompleto $(52,6 \%)$, em que $60,15 \%$ são do gênero masculino e $48,69 \%$ do gênero feminino, conforme pode ser verificado no Apêndice A. Percebe-se, ainda, que as mulheres possuem percentuais de graus de instrução maiores do que os homens, a partir do segundo grau, reforçando a hipótese do menor risco na tomada de decisão. Quanto ao tipo de moradia, a maioria possui domicílio próprio (78\%), e residem no Estado do Ceará (36\%).

Com relação ao microempreendimento, de 2005 até o ano de 2009, o lucro operacional variou, em média, de $\mathrm{R} \$ 1.104,00$ a $\mathrm{R} \$ 1.604,00$. Além disso, o lucro operacional difere entre homens e mulheres, em geral inferior para as últimas, no decorrer do período, de acordo com as estatísticas descritivas na Tabela 2. 
Tabela 2 - Estatísticas Descritivas do Lucro Operacional, por gênero e por faixas de lucro

\begin{tabular}{|c|c|c|c|c|c|c|c|c|c|}
\hline \multirow[b]{3}{*}{ Fluxos* } & \multirow[b]{3}{*}{ Estatísticas } & \multicolumn{2}{|l|}{ Gênero } & \multicolumn{6}{|c|}{ Faixas de Lucro } \\
\hline & & \multicolumn{2}{|c|}{ Lucro Total } & \multicolumn{2}{|c|}{ Abaixo de $\mathrm{R} \$ 1.000$} & \multicolumn{2}{|c|}{$\begin{array}{l}\text { Entre } R \$ 1.000 \mathrm{e} \\
2.000\end{array}$} & \multicolumn{2}{|c|}{ Acima de $R \$ 2.000$} \\
\hline & & Feminino & Masculino & Feminino & Masculino & Feminino & Masculino & Feminino & Masculino \\
\hline \multirow[t]{2}{*}{0} & Média & 888,21 & 1136,02 & 542,28 & 593,16 & 1346,63 & 1364,37 & 3082,29 & 3260,35 \\
\hline & Desvio Padrão & 787,61 & 1014,46 & 224,07 & 222,61 & 273,72 & 276,12 & 1226,69 & 1301,64 \\
\hline \multirow[t]{3}{*}{1} & Média & 1025,54 & 1256,32 & 586,97 & 624,67 & 1338,04 & 1377,57 & 3053,22 & 3181,15 \\
\hline & Desvio Padrão & 854,07 & 1038,84 & 219,86 & 214,03 & 268,44 & 275,70 & 1162,79 & 1291,48 \\
\hline & $\begin{array}{l}\text { Taxa de } \\
\text { Crescimento }\end{array}$ & 0,15 & 0,11 & 0,08 & 0,05 & $-0,01$ & 0,01 & $-0,01$ & $-0,02$ \\
\hline \multirow[t]{3}{*}{2} & Média & 1173,19 & 1419,15 & 636,87 & 670,18 & 1359,27 & 1382,22 & 3155,67 & 3241,29 \\
\hline & Desvio Padrão & 945,56 & 1122,45 & 212,75 & 204,23 & 271,60 & 267,08 & 1293,43 & 1350,85 \\
\hline & $\begin{array}{l}\text { Taxa de } \\
\text { Crescimento }\end{array}$ & 0,14 & 0,13 & 0,08 & 0,07 & 0,02 & 0,00 & 0,03 & 0,02 \\
\hline \multirow[t]{3}{*}{3} & Média & 1294,03 & 1601,29 & 636,31 & 669,79 & 1379,91 & 1410,79 & 3237,85 & 3368,01 \\
\hline & Desvio Padrão & 1057,95 & 1311,24 & 219,41 & 213,87 & 277,49 & 291,78 & 1373,90 & 1481,20 \\
\hline & $\begin{array}{l}\text { Taxa de } \\
\text { Crescimento }\end{array}$ & 0,1 & 0,13 & 0,00 & 0,00 & 0,02 & 0,02 & 0,03 & 0,04 \\
\hline \multirow[t]{3}{*}{4} & Média & 1438,51 & 1733,89 & 644,04 & 666,18 & 1413,45 & 1437,44 & 3337,91 & 3461,99 \\
\hline & Desvio Padrão & 1216,36 & 1406,23 & 225,18 & 216,23 & 283,13 & 293,20 & 1501,34 & 1539,31 \\
\hline & $\begin{array}{l}\text { Taxa de } \\
\text { Crescimento }\end{array}$ & 0,11 & 0,08 & 0,01 & 0,00 & 0,02 & 0,02 & 0,03 & 0,03 \\
\hline \multirow[t]{3}{*}{5} & Média & 1486,56 & 1831,78 & 648,67 & 677,71 & 1437,24 & 1452,99 & 3451,55 & 3561,95 \\
\hline & Desvio Padrão & 1260,13 & 1502,61 & 225,61 & 216,21 & 288,68 & 292,33 & 1506,88 & 1604,29 \\
\hline & $\begin{array}{l}\text { Taxa de } \\
\text { Crescimento }\end{array}$ & 0,03 & 0,06 & 0,00 & 0,02 & 0,02 & 0,01 & 0,03 & 0,03 \\
\hline
\end{tabular}

Fonte: Elaborada pelos autores com base nos registros administrativos do programa Crediamigo. *O fluxo 0 refere-se ao valor informado do lucro operacional no momento de entrada no programa.

O controle administrativo, uma característica subjetiva fornecida pelo agente de crédito, é na maior parte precário, seguido de satisfatório no primeiro período, com resultados semelhantes no último fluxo do ano de 2009. Observa-se que esses resultados são similares entre os gêneros, em que as mulheres apresentam um percentual de controle satisfatório maior do que o dos homens, 38,79\% e 35,68\%, respectivamente. 
Quanto ao tipo de negócio, a maioria possui negócio fixo (70\%) e com prazo de venda de um mês. O setor de atividade predominante dos clientes é o de comércio (92\%). Os valores dos empréstimos são, na maior parte, acima de $\mathrm{R} \$ 700,00$, e aumentam no decorrer dos fluxos. Além disso, o prazo do empréstimo com maior frequência varia de 3 a 4 meses. Essas características de empréstimo estimulam os clientes a poupar para pagar os empréstimos, gerando, assim, disciplina financeira.

A relação entre o lucro operacional e o valor do empréstimo é dada abaixo.

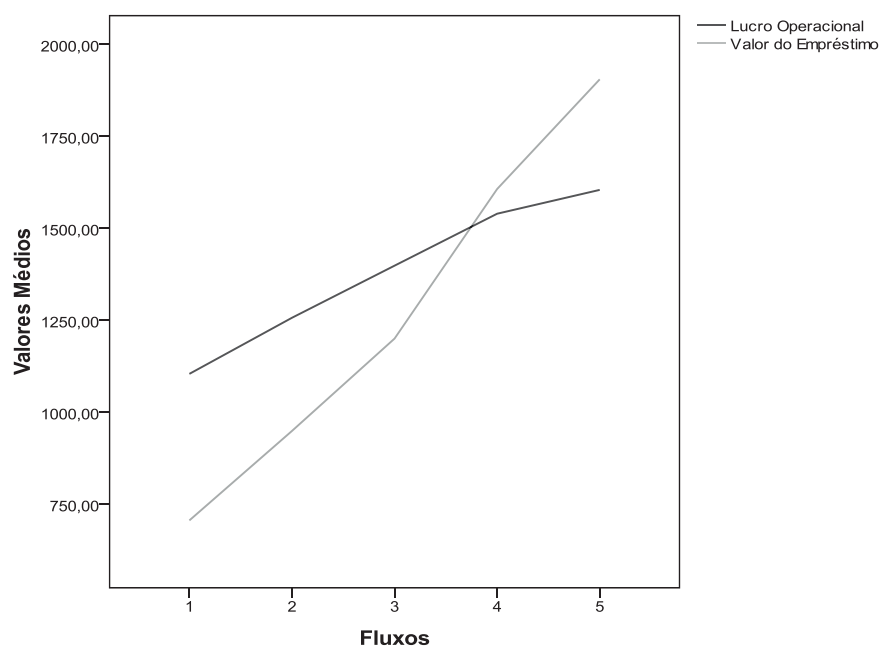

Gráfico 1 - Relação entre o lucro operacional e o valor do empréstimo

Fonte: Elaborada pelos autores com base nos registros administrativos do programa Crediamigo.

Esse resultado pode ser considerado um indicador de desempenho creditício, por conta das renovações e do aumento dos valores médios dos empréstimos no período analisado. A partir do quarto fluxo verifica-se uma inversão, na qual valor do empréstimo é maior que o do lucro operacional. Isso ocorre, em parte, porque à medida que o cliente permanece no Programa, ele pode adquirir empréstimos com valores maiores. Porém, isso também pode indicar a necessidade de maior atenção à capacidade empresarial, pois, no decorrer dos anos, aumentam os valores dos empréstimos. Para investigar a performance empresarial ao longo do tempo, estimamos a curva de crescimento, cujos resultados serão apresentados na próxima seção. 


\section{Resultados econométricos}

A Figura 1 mostra a tendência da trajetória de crescimento dada pela relação entre o Lucro Operacional e o período da informação por gênero. A análise exploratória ao longo do tempo sugere uma tendência de aumento lenta e similar entre os gêneros, confirmando o potencial de crescimento dos microempreendedores.

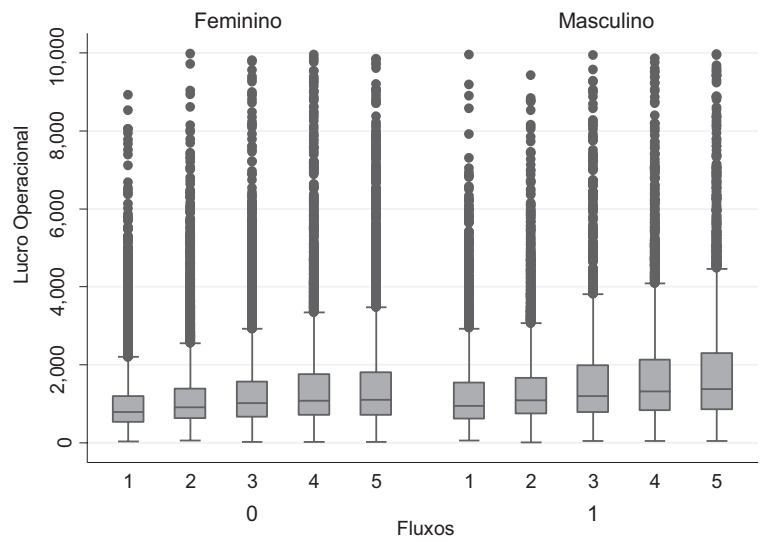

Figura 1- Trajetória de crescimento para homens e mulheres clientes do Crediamigo

Fonte: Elaborada pelos autores com base nos registros administrativos do programa Crediamigo.

Para qualificar o resultado acima, foram estimados modelos definidos pela expressão 3 da metodologia para o lucro operacional, tendo como variáveis explicativas o tempo de programa (linear e quadrático), e outras variáveis de controle representadas pelas características dos clientes e de seus microempreendimentos.

Inicialmente foi estimado um modelo único para homens e mulheres em conjunto, em que se observou que os efeitos aleatórios eram significativamente diferentes entre os gêneros. ${ }^{13}$ A partir desta constatação passou-se a estimar modelos diferentes para homens e mulheres.

Os modelos estimados de intercepto e coeficientes aleatórios estão expostos no Apêndice B para homens e mulheres. Na parte fixa do

${ }^{13}$ Foi utilizado o teste de razão de verossimilhança proposto em Rabe-Hesketh e Everitt (2012). 
modelo, os coeficientes das variáveis Tempo de Programa e Tempo de Programa ao quadrado são significantes ao nível de 5\%, permitindo a análise por meio de trajetórias de mudança dos microempreendedores individualmente ao longo do tempo. O coeficiente do tempo de programa foi estimado para os homens em $\mathrm{R} \$ 232,28$ e para as mulheres em $\mathrm{R} \$ 197,36$, indicando aumento do lucro operacional para ambos no período de 2005 a 2009, porém com um retorno maior para os primeiros. Para os coeficientes do tempo de programa ao quadrado, os resultados indicam que o lucro operacional cresce, porém a taxas decrescentes.

Para a parte aleatória do modelo, a estimativa do desvio padrão da inclinação aleatória é de $R$ \$212,47 para os homens e de $R$ \$164,19 para as mulheres. Ou seja, verifica-se que o retorno dos homens é maior, porém, a variabilidade neste retorno é menor para as mulheres. As estimativas dos desvios-padrão dos interceptos aleatórios para os homens e mulheres também reforçam o menor risco das mulheres. Enquanto para os homens este desvio padrão é de $\mathrm{R} \$ 433,98$, para as mulheres o valor estimado é de $\mathrm{R} \$ 247,51$. Vale destacar que a correlação significante entre os termos aleatórios do intercepto e inclinação sanciona o uso da matriz de variância não estruturada para os modelos.

Como visto, um aspecto considerado na literatura sobre microcrédito é a importância das mulheres, que se mostram mais confiáveis do que os homens no que tange ao pagamento dos empréstimos, na maximização do lucro, além da elevação dos níveis de educação e nutrição dos filhos. Segundo FIDA (2009), as mulheres repõem melhor o investimento e têm maior propensão para a poupança. Além disso, as mulheres tendem a se mudar menos do que os homens, o que diminui o risco de inadimplência e promove trajetórias de crescimento mais conservadoras, o que está se observando nos resultados.

Após a estimação dos modelos, descrevemos na Figura 2 a trajetória média estimada para os clientes permanecentes no programa do gênero masculino e feminino, obtida a partir da matriz de covariância dada pela parte fixa do modelo, juntamente com os limites nos quais se espera que 95\% da trajetória do indivíduo estejam situados. 


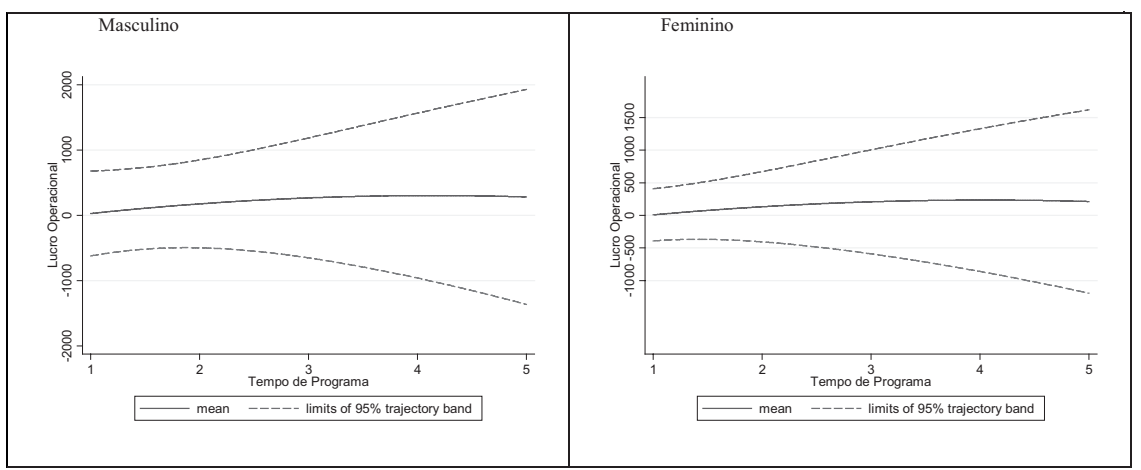

Figura 2 - Trajetória média e faixa de 95\% da trajetória do indivíduo, para homens e mulheres, respectivamente

Fonte: Elaborada pelos autores com base nos registros administrativos do programa Crediamigo.

Verifica-se visualmente maior dispersão da curva de crescimento da média do lucro operacional dos clientes do gênero masculino. As ações dos programas de microcrédito, de forma geral, concentram-se nos empréstimos para as mulheres, por considerá-las mais participativas e comprometidas com o programa. Ao acompanhar os homens ao longo do tempo, verifica-se maior dispersão dos valores de lucro declarados, o que pode indicar maior risco para estes, e uma atitude mais conservadora para as mulheres, principalmente nos períodos iniciais. Isso pode ser percebido também pelo intervalo abaixo da curva de crescimento que, para os homens, atinge valores negativos maiores do que os das mulheres. Apesar do maior risco para os homens, o seu retorno médio é levemente maior, sendo melhor percebido apenas pelo coeficiente do tempo de programa nas equações estimadas.

Observa-se ainda que o lucro médio para homens e mulheres situa-se abaixo de $\mathrm{R} \$ 500,00$ durante toda a trajetória de crescimento, indicando que a clientela do programa é de baixa renda. Embora o foco esteja como desejado, o efeito de rendimentos decrescentes sugere o desenvolvimento de mecanismos apropriados de monitoramento constante dos clientes.

Com relação aos outros determinantes do lucro operacional, os resultados estimados seguem o que é visto na literatura, como nas pesquisas de Barreto et al. (2010) e Neri (2008). Porém, algumas 
considerações merecem destaque no que se refere ao diferencial de gênero. $\mathrm{O}$ efeito da variável indicativa de possuir outras rendas é negativo e pontualmente maior para os homens, significando que a substituição do esforço gerado por outros rendimentos é menor nas mulheres, mostrando uma dedicação relativamente maior com o seu empreendimento.

Como a trajetória de crescimento pode variar com o estágio inicial com que o microempreendimento entra no programa, foram estimados modelos para amostras diferenciadas por lucro operacional de entrada no programa, que pode ser entendido como o tamanho da microempresa ao entrar no Crediamigo. Com estes modelos, é possível analisar a relação entre lucro operacional inicial e as trajetórias de crescimento. Por exemplo, clientes com lucros iniciais maiores podem ter tendência de aumento mais lento do lucro operacional ao longo do tempo. Os segmentos de clientes estão separados da seguinte forma: para valores de lucro operacional no primeiro fluxo de 2005 , abaixo de $R \$ 1.000,00$, temos 1.959 clientes do gênero masculino e 4.494 do gênero feminino; entre $R \$ 1.000,00$ e 2.000,00, temos 858 homens e 1.318 mulheres; e, na última faixa, acima de $\mathrm{R} \$$ 2.000,00, temos 408 homens e 433 mulheres.

Os resultados das estimativas destes modelos estão contidos no Apêndice C. Apesar do foco do programa ser nas mulheres, os resultados estimados continuam mostrando que os homens possuem um retorno um pouco maior que as mulheres para as primeiras faixas de renda. Para a faixa de renda mais alta de lucro operacional inicial sequer existe uma inclinação positiva significante para ambos os gêneros, sugerindo ausência de equação de crescimento. Estes resultados também podem ser vistos na Figura 3, que mostra as trajetórias médias estimadas para os clientes do gênero masculino e feminino de acordo com as faixas de lucro operacional inicial citadas anteriormente.

Para as faixas de lucro operacional abaixo de $\mathrm{R} \$ 1.000,00$, e entre este valor e $\mathrm{R} \$ 2.000,00$, verificam-se trajetórias de crescimento quadráticas em acordo com o conjunto total da amostra. Mas para aqueles que entram no programa com o lucro inicial acima de $\mathrm{R} \$$ 2.000,00 verifica-se uma ausência de inclinação positiva na trajetória de crescimento tanto para homens como para mulheres. Destaca-se, neste caso, que a média do lucro operacional é maior para as mu- 
lheres, mas sem evolução no decorrer do programa. Esses resultados podem explicar a inversão de tendência de crescimento dos valores médios dos lucros operacionais e dos empréstimos apresentados no Gráfico 1.

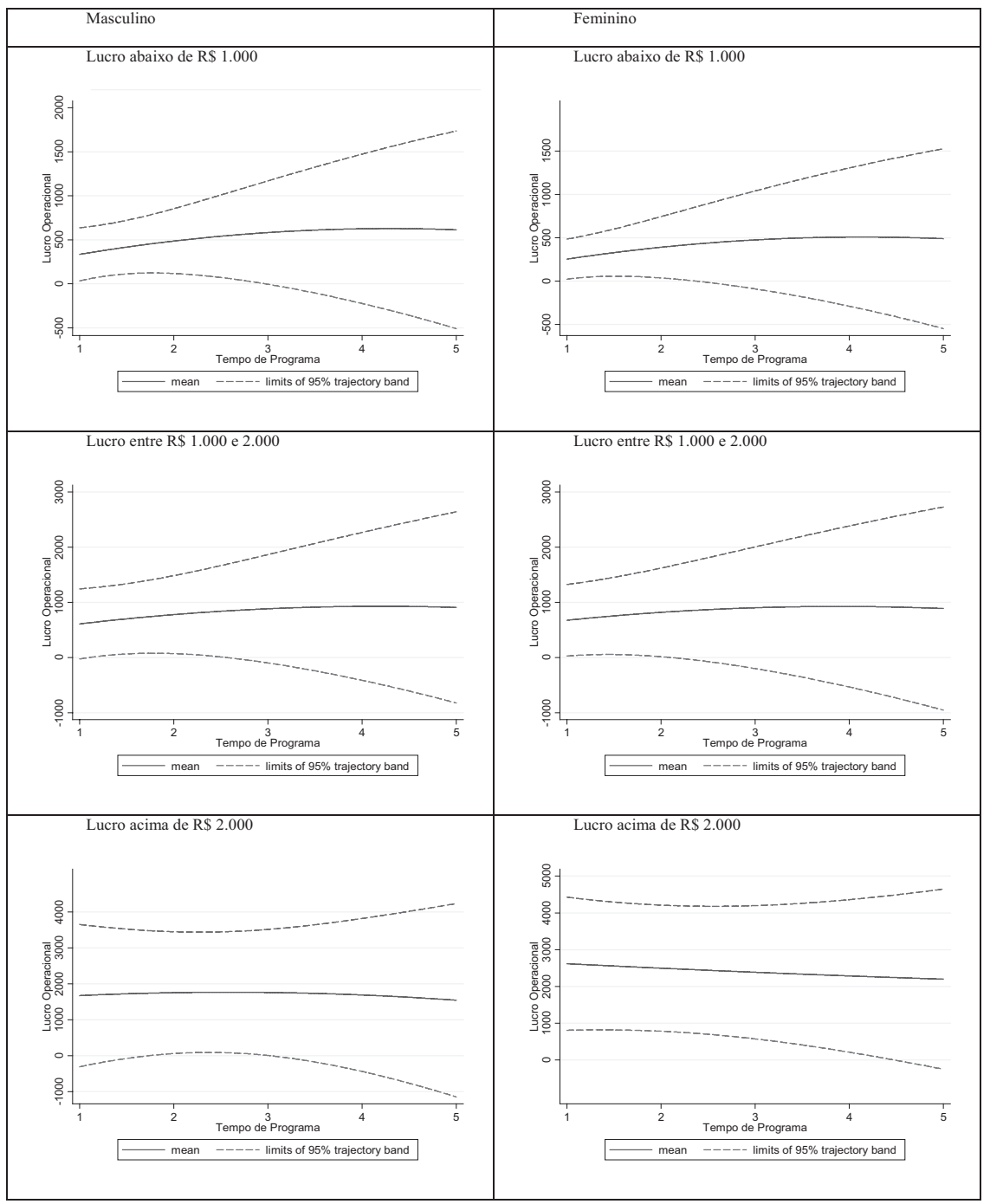

Figura 3 - Trajetória média e faixa de $95 \%$ da trajetória do indivíduo, para homens e mulheres, respectivamente, para lucro operacional no primeiro fluxo abaixo de R\$ 1.000; entre R\$ 1.000 e 2.000; e, acima de $\mathrm{R} \$ 2.000$

Fonte: Elaborada pelos autores com base nos registros administrativos do programa Crediamigo. 
Interessante destacar novamente o efeito de possuir outras rendas no lucro operacional. Na faixa de lucro abaixo de $\mathrm{R} \$ 1.000,00$ e entre $\mathrm{R} \$ 1.000,00$ e 2.000,00, o desempenho dos homens é melhor do que o das mulheres. Porém, para lucros iniciais acima de $\mathrm{R} \$ 2.000,00$ ocorre uma inversão, o que pode explicar em parte o desempenho das mulheres encontrado na análise gráfica anterior.

Portanto, a análise por grupos de lucro operacional inicial certificou a presença de rendimentos decrescentes nas trajetórias de crescimento tanto para homens como para mulheres. Este fator indica a necessidade de não relaxar o monitoramento ao longo do tempo para os clientes, promovendo treinamento e assistência técnica que possam reverter este decaimento do lucro após certo período. Isto é ainda mais necessário para aqueles microempreendimentos um pouco maiores, e para as mulheres que possuem uma taxa de retorno inicial um pouco menor. Por outro lado, estas mostraram ter trajetórias de crescimento menos arriscadas, o que é importante para a sustentabilidade e crescimento do programa de microcrédito que possui um viés de captação de clientes a favor das microempreendedoras.

Com esses resultados, percebe-se também que as mulheres, mesmo trabalhando muitas horas em casa, são capazes de exercer o seu papel econômico fora da família ao obter êxito nos empreendimentos, o que tende a melhorar a sua posição relativa, gerando importantes mudanças na sociedade.

\section{Considerações finais}

O presente trabalho discutiu o desempenho dos clientes do Programa Crediamigo por meio da estimação de trajetórias de crescimento do lucro operacional de seus microempreendimentos. Os resultados obtidos na análise dos dados em painel indicam tendências de crescimento diferentes para homens e mulheres e para diferentes faixas iniciais de lucro operacional.

A utilização de modelos lineares mistos com coeficiente aleatório para estimar as curvas de crescimento possibilitou verificar a existência das mesmas para microempreendimentos que entram no programa com lucros operacionais abaixo de $\mathrm{R} \$ 2.000,00$. Também 
foi possível constatar, com o uso da metodologia, que os homens possuem um retorno um pouco maior que as mulheres com relação à evolução do lucro. No entanto, estas últimas possuem trajetórias mais estáveis, o que fortalece a hipótese de preferências diferencias por riscos para homens e mulheres (Croson; Gneezy, 2009). Ou seja, estas últimas preferem evoluções conservadoras no negócio, o que é importante para a sustentabilidade do próprio programa de microcrédito. Neste aspecto, a tendência do programa em dar preferência a grupos solidários com um maior número de mulheres se justifica.

Por outro lado, é preciso fortalecer o monitoramento, a assistência técnica e operacional para que os microempreendimentos, mesmo com escalas tão pequenas, não sofram declínios temporais, sendo que estes começam em média a partir do quarto ano de programa tanto para homens quanto para mulheres. Destaque ainda maior para os microempreendimentos com lucros maiores de $\mathrm{R} \$ 2.000,00$ na entrada, e administrados por mulheres.

A evidência de trajetória de crescimento é positiva para a avaliação do próprio programa de microcrédito. Vale destacar, no entanto, que os resultados encontrados neste trabalho podem conter viés de seleção da amostra, pois somente aqueles que renovam créditos por cinco anos permanecem na amostra. Se os que deixam o programa o fazem por incapacidade de pagamento, é possível que a trajetória do programa como um todo seja diferente da trajetória encontrada. Em condição oposta, também é possível que os desligamentos sejam casos de sucesso, em que os microempreendedores procuram modalidades de empréstimos maiores, muitas vezes até mais baratas, como as providas por fundos públicos. Como o Crediamigo possui uma inadimplência muito baixa, e a migração para outros programas de crédito é um relato usual dos agentes de crédito, é possível que as trajetórias de crescimento sejam ainda maiores. Estas possibilidades demandam estudos mais detalhados a partir de um monitoramento dos clientes, mesmo posterior a sua saída do programa. No caso do Crediamigo, a interlocução de programas poderia ser facilitada pelo fato de a instituição financeira prover diversas modalidades de crédito.

O fornecimento de microcrédito pode proporcionar vantagens econômicas, políticas e sociais quando contribuem para que os microempreendimentos se tornem mais dinâmicos e capazes de evoluir. $\mathrm{Ou}$ 
seja, por meio desse instrumento é possível valer-se das oportunidades na economia, proporcionando ainda uma melhor inserção social em várias dimensões. Para as mulheres, em particular, a possibilidade de crédito não apenas aumenta as suas possibilidades empreendedoras como também promovem um comportamento social ativo via grupos solidários ou comunitários.

\section{Referências}

ABDUL LATIF JAMEEL POVERTY ACTION LAB. Where credit is due. Disponível em: < http://www. povertyactionlab.org/publication/where-credit-is-due> $>$. Acesso em: 01 mai. 2015.

AGHION, B.; MORDUCH, J. The Economics of Microfinance. Cambridge: MIT Press, 2005.

BADUNENKO, OLEG; BARASINSKA, NATALIYA; SCHÄFER, DOROTHEA. Risk attitudes and investment decisions across European countries: are women more conservative investors than men? Working Paper / FINESS 6.1, DIW Berlin, German Institute for Economic Research. 2009.

BANCO DO NORDESTE DO BRASIL (BNB). Crediamigo. Disponível em: $<$ http://www.bnb.gov. br/content/aplicacao/Produtos_e Servicos/Crediamigo/gerados/Resultados.asp $>$. Acesso em 10 jul. 2013.

BANERJEE, A. Microcredit under the microscope: what have we learned in the past two decades, and what do we need to know? Annual Reviews of Economics 5, 487-519, 2013.

BARRETO, F. A. F. D.; SOARES, R. B.; TEIXEIRA, M. A. Saindo da pobreza com microcrédito. Condicionantes e tempo de ascensão: o caso dos clientes do crediamigo. Disponível em: $<$ http:// www.caen.ufc.br/ ataliba/ensaiocatorze>. Acesso em: 15 jul. 2010.

BÖNTE, W.; JAROSCH, M. Gender differences in competitiveness, risk tolerance, and other personality traits: do they contribute to the gender gap in entrepreneurship? Schumpeter discussion papers 2011-012. Schumpeter School of Business and Economics, University of Wuppertal, 2011.

BRYK, A.; RAUDENBUSH, S. A hierarchical model for studying school effects. Sociology of Education, v. 59, n. 1 (Jan., 1986), 1-17. Disponível em: <http://personal.psc.isr.umich.edu/yuxie-web/ files/soc543-2004/Raudenbush_Bryk1986.pdf>. Acesso em: 19 mar. 2013.

CARREÑO, N. S., ESCOLAR, H. A. H., SAYAGO, J. A. M. Microcrédito y bienestar: uma evaluación empírica. Disponível em: <http://www.scielo.org.co/pdf/soec/n21/n21a09.pdf>. Acesso em: 19 mar. 2013.

CHESTON, S. Just the facts, ma'am: gender stories from unexpected sources with morals from microfinance, Ada Dialogue, 2006. Disponível em: $<$ http://www.genfinance.info/documents/Gender\%20 Impact/Cheston_JusttheFactsMaam_2006.pdf>. Acesso em: 02 ago. 2013.

COSTA, F. N. da. Microcrédito no brasil. Campinas: IE/UNICAMP, 2012. (Texto para discussão n. 175).

CROSON, R.; GNEEZY, U. Gender Differences in Preferences. Journal of Economic Literature, 47:2, $1-27,2009$.

DUFLO, E. Women Empowerment and Economic Development. National Bureau of Economic Research Working Paper 17702, 2011.

FÁVERO, L.P.; BELFIORE, P.; SILVA, F, L.; CHAN, B, L. Análise de dados: modelagem multivariada para tomada de decisões. Rio de Janeiro: Elsevier, 2009. 
FERNANDES, J. A. A. A importância do género no desenvolvimento das actividades do microcrédito: caso português. Disponível em: $<$ https://www.repository.utl.pt/bitstream/10400.5/2390/1/A\%20 import $\% \mathrm{c} 3 \% \mathrm{a} 2 \mathrm{ncia} \% 20 \mathrm{do} \% 20 \mathrm{~g} \% \mathrm{c} 3 \% \mathrm{a} 9$ nero\%20no\%20desenvolvimento\%20das\%20actividades\%20d.pdf $>$. Acesso em: 01 ago. 2013.

FIDA. Gender and rural microfinance: reaching and empowering women. 2009. Disponível em: $<$ http:// www.ifad.org/gender/pub/gender_finance.pdf $>$. Acesso em: 02 ago. 2013.

FONTES, A.; PERO, V. Determinantes do desempenho dos microempreendedores no brasil. Disponível em: $<$ http://www.ie.ufri.br/datacenterie/pdfs/seminarios/pesquisa/texto0906.pdf $>$. Acesso em: 03 fev. 2013.

FOSSEN, F. M. Gender Differences in Entrepreneurial Choice and Risk Aversion - A Decomposition Based on a Microeconometric Model. Discussion Paper 936, 2009.

MATLARY, F. H. What determines microenterprise growth? Disponível em: $<$ http://brage.bibsys.no/ nhh/bitstream/URN:NBN:no-bibsys_brage 34409/1/Matlary2012.PDF>. Acesso em: 06 set. 2013.

MEL, S.; MCKENZIE, D.; WOODRUFF, C. Who does microfinance fail to reach? Experimental evidence on gender and microenterprise returns. BREAD Working Paper No. 157, 2007.

MONZONI NETO, M. P. Impacto em renda do microcrédito: uma investigação empírica sobre geração de renda do crédito popular solidário (São Paulo Confia), no município de São Paulo. - Escola de Administração de Empresas de São Paulo, Fundação Getúlio Vargas, São Paulo, 2006. Disponível $\mathrm{em}:\langle$ http://bibliotecadigital.fgv.br/dspace/bitstream/handle/10438/2499/61768.pdf? sequence=2 $>$. Acesso em: 16 mar. 2013.

NERI, M. C. Microcrédito. O mistério nordestino e o grameen brasileiro. Perfil e performance dos clientes do Crediamigo. Editora da Fundação Getúlio Vargas, 375 p., 2008.

PITT, M.; KHANDKER, S. R. The Impact of Group-Based Credit Programs on Poor Households in Bangladesh: Does the Gender of the Participant Matter? Journal of Political Economy 106: 958-996, 1998.

PITT, M. M.; KHANDKER, S. R.; CARTWRIGHT, J. Does micro-credit empower women: evidence from Bangladesh. Policy Research Working Paper Series 2998, The World Bank, 2003.

RABE-HESKETH, S.; EVERITT, B. S. A Handbook of Statistical Analyses Using Stata. Boca Raton, FL: Chapman \& Hall/CRC, Ed. 4, 2006.

RABE-HESKETH, S.; SKRONDAL, A. Multilevel and Longitudinal Modeling Using Stata. Texas, Stata Press Corporation, 2012.

RIGHETTI, C. C. B. Efeitos do microcrédito na geração de renda em microempreendimentos: avaliação de impactos do programa real microcrédito. Disponível em: $<$ http://bibliotecadigital.fgv.br/ dspace/bitstream/handle/10438/2576/71050100663.pdf?sequence=3>. Acesso em: 20 nov. 2012.

SEN, A. Desenvolvimento como liberdade. Tradução Laura Teixeira Mota. $1^{\mathrm{a}}$ reimpressão. São Paulo: Companhia das Letras, 2000. $410 \mathrm{p}$.

SCHÖR, H. The profile of the successful entrepreneur, results of the survey "factors of business success", 2006. Disponível em: $<$ http://epp.eurostat.ec.europa.eu/cache/ITY_OFFPUB/KS-NP-06-029/EN/ KS-NP-06-029-EN.PDF>. Acesso em: 05 ago. 2013.

STATACORP. Stata: Release 12. Statistical Software. College Station, TX: StataCorp LP, 2011.

YUNUS, M. O banqueiro dos pobres. Londres: Public Affairs, 1999, 343p.

WEST, B. T.; WELCH, K. B.; GALECKI, A. T. Linear mixed models. A practical guide using statistical software. Boca Raton, FL: Chapman \& Hall/CRC, 2009.

WOOLDRIDGE, J.M. Econometric Analysis of Cross-Section and Panel Data. Cambridge: The MIT Press, 2002. 


\section{APÊNDICE}

APÊNDICE A - Estatísticas Descritivas (\%)

\begin{tabular}{|c|c|c|c|}
\hline & Masculino & Feminino & Total \\
\hline \multicolumn{4}{|l|}{ Grau de instrução } \\
\hline Analfabeto & 4,39 & 2,02 & 2,83 \\
\hline Primeiro grau incompleto & 60,15 & 48,69 & 52,59 \\
\hline Primeiro grau completo & 13,44 & 13,38 & 13,40 \\
\hline Segundo grau incompleto & 3,87 & 4,70 & 4,42 \\
\hline Segundo grau completo & 16,76 & 26,98 & 23,50 \\
\hline Superior incompleto & 0,52 & 1,35 & 1,06 \\
\hline Superior completo & 0,84 & 2,86 & 2,17 \\
\hline \multicolumn{4}{|l|}{ Tipo de moradia } \\
\hline Domicílio próprio & 77,67 & 78,19 & 78,02 \\
\hline Domicílio alugado & 7,63 & 7,23 & 7,37 \\
\hline Domicílio familiar & 4,48 & 3,91 & 4,11 \\
\hline Domicílio outros & 8,34 & 8,66 & 8,55 \\
\hline Domicílio emprestado & 1,87 & 2,00 & 1,96 \\
\hline \multicolumn{4}{|l|}{ Controle administrativo } \\
\hline Precário & 43,41 & 43,45 & 43,44 \\
\hline Nenhum & 12,25 & 9,15 & 10,20 \\
\hline Bom & 8,65 & 8,61 & 8,62 \\
\hline Satisfatório & 35,68 & 38,79 & 37,73 \\
\hline \multicolumn{4}{|l|}{ Tipo de negócio } \\
\hline Fixo & 79,50 & 66,79 & 71,12 \\
\hline Ambulante & 20,49 & 33,21 & 28,88 \\
\hline \multicolumn{4}{|l|}{ Prazo do empréstimo } \\
\hline À vista & 37,56 & 21,99 & 27,29 \\
\hline Parcelado & 62,44 & 78,01 & 72,71 \\
\hline \multicolumn{4}{|l|}{ Setor de atividade } \\
\hline Comércio & 88,59 & 93,81 & 92,03 \\
\hline Indústria & 2,78 & 2,81 & 2,80 \\
\hline Serviço & 8,63 & 3,38 & 5,17 \\
\hline \multicolumn{4}{|l|}{ Estado da Federação } \\
\hline CE & 36,61 & 36,16 & 36,31 \\
\hline AL & 6,54 & 7,04 & 6,87 \\
\hline MA & 11,96 & 9,91 & 10,61 \\
\hline RN & 3,75 & 4,53 & 4,27 \\
\hline ES & 0,12 & 0,16 & 0,15 \\
\hline PI & 8,00 & 9,64 & 9,08 \\
\hline PE & 7,82 & 7,65 & 7,71 \\
\hline BA & 10,10 & 10,37 & 10,28 \\
\hline$M G$ & 2,64 & 2,63 & 2,63 \\
\hline SE & 4,50 & 4,04 & 4,19 \\
\hline PB & 7,94 & 7,88 & 7,90 \\
\hline
\end{tabular}

Fonte: Elaborada pelos autores com base nos registros administrativos do programa Crediamigo. 
APÊNDICE B- Estimativa de máxima verossimilhança do crescimento do lucro operacional dos clientes do Crediamigo por gênero

\begin{tabular}{|c|c|c|c|c|}
\hline \multirow{2}{*}{ Lucro Operacional } & \multicolumn{2}{|c|}{ Masculino } & \multicolumn{2}{|c|}{ Feminino } \\
\hline & Coeficiente & Erro Padrão & Coeficiente & Erro Padrão \\
\hline \multicolumn{5}{|l|}{ Parte Fixa } \\
\hline $1^{\circ}$ Grau Incompleto & 5,98 & $(45,08)$ & 39,09 & $(39,85)$ \\
\hline $1^{\circ} \mathrm{Grau}$ & 16,88 & $(49,13)$ & 61,25 & $(41,38)$ \\
\hline $2^{\circ}$ e $3^{\circ}$ Graus & $98,78^{*}$ & $(49,27)$ & $95,34^{*}$ & $(40,73)$ \\
\hline Domicílio Alugado & 27,32 & $(34,75)$ & 14,69 & $(21,52)$ \\
\hline Domicílio Família & $-112,74^{*}$ & $(45,32)$ & $-50,70$ & $(28,87)$ \\
\hline Domicílio Outros & $-25,58$ & $(33,88)$ & $-43,67^{\star}$ & $(19,96)$ \\
\hline Lucro Operacional Primeiro Fluxo & $0,60^{*}$ & $(0,01)$ & $0,64^{*}$ & $(0,01)$ \\
\hline Outras Rendas & 0,01 & $(0,02)$ & $0,03^{*}$ & $(0,01)$ \\
\hline Dummy Outras Rendas & $-271,47^{\star}$ & $(18,76)$ & $-224,26^{*}$ & $(11,70)$ \\
\hline Quantidade de Operações & $16,15^{\star}$ & $(3,81)$ & $13,70^{*}$ & $(2,34)$ \\
\hline Tempo de Programa & $232,28^{*}$ & $(22,82)$ & $197,36^{*}$ & $(14,07)$ \\
\hline Tempo de Programa Quadrado & $-28,09^{*}$ & $(3,36)$ & $-24,38^{*}$ & $(2,07)$ \\
\hline Tempo de Atividade & 0,50 & $(1,36)$ & 1,16 & $(0,91)$ \\
\hline Controle Administrativo Precário & 14,07 & $(27,49)$ & 8,26 & $(18,14)$ \\
\hline Controle Administrativo Bom & $97,78^{*}$ & $(37,99)$ & $90,34^{*}$ & $(24,00)$ \\
\hline Controle Administrativo Satisfatório & $69,81^{*}$ & $(28,61)$ & $51,58^{*}$ & $(18,80)$ \\
\hline Negócio Ambulante & $-32,80$ & $(22,37)$ & $-66,15^{\star}$ & $(11,85)$ \\
\hline Vendas Prazo 1 & 0,68 & $(18,38)$ & $-10,72$ & $(12,95)$ \\
\hline Vendas Prazo 2 & $89,33^{*}$ & $(40,25)$ & 8,72 & $(17,55)$ \\
\hline Vendas Prazo 3 & 103,43 & $(81,70)$ & 48,55 & $(43,25)$ \\
\hline Indústria & 50,68 & $(54,24)$ & $-65,12^{*}$ & $(32,71)$ \\
\hline Serviço & $-106,93^{\star}$ & $(32,28)$ & $-33,49$ & $(29,55)$ \\
\hline Valor Empréstimo & $0,35^{*}$ & $(0,01)$ & $0,34^{*}$ & $(0,01)$ \\
\hline Participação no Empréstimo & $-0,25$ & $(0,41)$ & $-0,05$ & $(0,24)$ \\
\hline Prestação 4m & $-15,11$ & $(22,17)$ & $-59,00^{*}$ & $(14,24)$ \\
\hline Prestação 5m & $-18,87$ & $(28,53)$ & $-73,50^{\star}$ & $(17,87)$ \\
\hline Prestação 6m & $-45,10$ & $(30,63)$ & $-91,00^{\star}$ & $(19,52)$ \\
\hline Prestação acima $6 \mathrm{~m}$ & $-260,58^{*}$ & $(40,21)$ & $-342,67^{\star}$ & $(26,76)$ \\
\hline MA & $229,07^{\star}$ & $(32,12)$ & $201,98^{*}$ & $(20,98)$ \\
\hline $\mathrm{AL}$ & $175,58^{*}$ & $(39,66)$ & $157,20^{*}$ & $(23,54)$ \\
\hline RN & $184,55^{\star}$ & $(50,48)$ & $192,73^{\star}$ & $(28,33)$ \\
\hline $\mathrm{Pl}$ & $134,87^{*}$ & $(37,12)$ & $107,89^{*}$ & $(20,99)$ \\
\hline ES & 374,85 & $(265,69)$ & $268,19^{*}$ & $(138,36)$ \\
\hline PE & $172,56^{*}$ & $(38,55)$ & $154,12^{*}$ & $(23,69)$ \\
\hline $\mathrm{BA}$ & $186,34^{*}$ & $(35,00)$ & $177,28^{*}$ & $(21,17)$ \\
\hline$M G$ & $129,69^{*}$ & $(60,63)$ & $101,20^{\star}$ & $(36,88)$ \\
\hline SE & $121,59^{\star}$ & $(47,02)$ & $85,39^{*}$ & $(30,05)$ \\
\hline PB & $288,05^{\star}$ & $(37,73)$ & $197,36^{\star}$ & $(22,95)$ \\
\hline Constante & $-176,45^{\star}$ & $(86,49)$ & $-165,28^{*}$ & $(60,53)$ \\
\hline \multicolumn{5}{|l|}{ Parte Aleatória } \\
\hline sd(_cons) & $433,98^{*}$ & & $247,51^{*}$ & \\
\hline sd(Tempo de Programa) & $212,47^{\star}$ & & $164,19^{\star}$ & \\
\hline corr(tp, _cons) & $-0,69^{*}$ & & $-0,59^{\star}$ & \\
\hline sd(Residual) & $648,32^{*}$ & & $554,33^{*}$ & \\
\hline Log likelihood & $-130360,21$ & $-247160,93$ & & \\
\hline
\end{tabular}

Fonte: Elaborada pelos autores com base nos registros administrativos do programa Crediamigo.

* Estatisticamente significante ao nível de confiança de 95\%.

Variáveis omitidas: Quando for variável binária é o complemento. Demais variáveis omitidas: Analfabeto, Domicílio Próprio, Nenhum Controle Administrativo, Negócio Fixo, Vendas à Vista, Comércio, Prestação 3 meses e unidade de federação Ceará. 
APÊNDICE C- Estimativa de máxima verossimilhança do crescimento do lucro operacional dos clientes do Crediamigo, por gênero e faixas de lucro operacional

\begin{tabular}{|c|c|c|c|c|c|c|}
\hline \multirow[t]{3}{*}{ Lucro Operacional } & \multicolumn{6}{|l|}{ Coeficientes } \\
\hline & Masculino & Feminino & Masculino & Feminino & Masculino & Feminino \\
\hline & \multicolumn{2}{|c|}{ Abaixo $\mathrm{R} \$ 1.000$} & \multicolumn{2}{|c|}{ Entre $R \$ 1.000$ e 2.000} & \multicolumn{2}{|c|}{ Acima $R \$ 2.000$} \\
\hline \multicolumn{7}{|l|}{ Parte Fixa } \\
\hline 1ํ Grau Incompleto & 0,88 & $77,92^{*}$ & 163,35 & 63,57 & $-274,26$ & $-341,55$ \\
\hline $1^{\circ} \mathrm{Grau}$ & 63,39 & $122,66^{*}$ & 138,97 & 67,89 & $-45,98$ & $-195,54$ \\
\hline $2^{\circ}$ e $3^{\circ}$ Graus & $85,96^{*}$ & $127,71^{\star}$ & $228,50^{*}$ & 213,98 & $-1,46$ & $-236,77$ \\
\hline Domicílio Alugado & 14,80 & $-13,99$ & $-87,16$ & $-20,35$ & 353,92 & 156,31 \\
\hline Domicílio Família & $-133,68^{*}$ & $-58,81^{*}$ & $-184,38$ & 23,31 & $-422,13$ & $-469,69$ \\
\hline Domicílio Outros & $-0,29$ & $-50,60^{*}$ & $-35,89$ & $-45,41$ & $-29,03$ & $-141,52$ \\
\hline Outras Rendas & $-0,08^{*}$ & $-0,01$ & 0,07 & $0,09^{*}$ & $0,18^{*}$ & $0,14^{*}$ \\
\hline Dummy Outras Rendas & $-235,38^{*}$ & $-225,82^{*}$ & $-340,60^{*}$ & $-280,21^{*}$ & $-382,81^{*}$ & $-408,12^{*}$ \\
\hline Quantidade de Operações & $12,85^{*}$ & $12,64^{*}$ & $30,86^{*}$ & $14,94^{*}$ & 26,85 & 29,09 \\
\hline Tempo de Programa & $231,53^{\star}$ & $214,60^{*}$ & $262,34^{*}$ & $234,13^{*}$ & 195,51 & $-138,43$ \\
\hline Tempo de Programa Quadrado & $-26,97^{*}$ & $-25,95^{\star}$ & $-31,25^{*}$ & $-30,16^{*}$ & $-37,94^{*}$ & 5,56 \\
\hline Tempo de Atividade & 2,15 & 1,27 & 1,63 & 1,65 & 2,05 & 3,79 \\
\hline Controle Administrativo Precário & 12,21 & 20,75 & 35,79 & 20,53 & 192,86 & $-477,80^{*}$ \\
\hline Controle Administrativo Bom & $86,31^{*}$ & $71,15^{\star}$ & 86,90 & $183,24^{*}$ & 409,74 & $-159,29$ \\
\hline Controle Administrativo Satisfatório & $66,60^{*}$ & $66,85^{*}$ & 12,76 & 119,41 & 396,57 & $-200,55$ \\
\hline Negócio Ambulante & $-12,81$ & $-71,52^{*}$ & $-75,35$ & $-127,16^{\star}$ & $-195,15$ & $-647,88^{*}$ \\
\hline Vendas Prazo 1 & $-18,97$ & $-17,01$ & 54,56 & $-27,04$ & $-72,94$ & $-17,63$ \\
\hline Vendas Prazo 2 & 63,32 & $-12,11$ & 55,58 & 16,31 & 172,89 & 203,41 \\
\hline Vendas Prazo 3 & $257,25^{\star}$ & $93,66^{*}$ & 57,23 & $-2,18$ & $-125,76$ & 153,33 \\
\hline Indústria & 56,52 & $-120,82^{*}$ & 116,13 & $-12,94$ & $-107,16$ & 2,54 \\
\hline Serviço & $-71,80^{*}$ & $-22,85$ & $-179,60^{*}$ & $-166,00^{\star}$ & $-337,02$ & 30,02 \\
\hline Valor Empréstimo & $0,39^{*}$ & $0,36^{*}$ & $0,30^{*}$ & $0,37^{\star}$ & $0,40^{\star}$ & $0,39^{*}$ \\
\hline Participação no Empréstimo & $-0,11$ & 0,10 & $-0,28$ & 0,50 & $-0,21$ & 0,23 \\
\hline Prestação $4 \mathrm{~m}$ & $-9,32$ & $-32,83^{*}$ & $-32,76$ & $-69,42$ & $-66,17$ & $-253,69^{*}$ \\
\hline Prestação 5m & $-46,40^{*}$ & $-37,37^{\star}$ & 1,08 & $-126,88^{*}$ & $-31,86$ & $-283,66^{*}$ \\
\hline Prestação 6m & $-56,36^{*}$ & $-61,04^{*}$ & $-69,35$ & $-154,03^{\star}$ & $-79,36$ & $-262,92^{*}$ \\
\hline Prestação acima $6 \mathrm{~m}$ & $-278,77^{*}$ & $-284,94^{*}$ & $-220,41^{*}$ & $-570,05^{\star}$ & $-519,92^{*}$ & $-531,07^{*}$ \\
\hline MA & $281,92^{*}$ & $286,73^{\star}$ & $340,80^{*}$ & $351,20^{*}$ & 247,00 & $433,26^{*}$ \\
\hline$A L$ & $192,03^{*}$ & $249,42^{*}$ & $266,69^{*}$ & $292,54^{*}$ & 460,33 & 195,84 \\
\hline $\mathrm{RN}$ & $155,82^{*}$ & $172,49^{*}$ & $411,40^{*}$ & $358,67^{\star}$ & 448,04 & 583,66 \\
\hline $\mathrm{PI}$ & $172,69^{*}$ & $171,61^{*}$ & 122,59 & $196,26^{*}$ & $578,12^{*}$ & 68,63 \\
\hline ES & $845,78^{\star}$ & 309,40 & Omitido & 343,37 & 105,12 & $1455,41^{*}$ \\
\hline PE & $101,99^{*}$ & $109,26^{*}$ & 72,71 & $385,51^{*}$ & $1005,92^{*}$ & 384,36 \\
\hline $\mathrm{BA}$ & $207,32^{*}$ & $243,64^{*}$ & $190,89^{*}$ & $266,43^{*}$ & $541,71^{*}$ & $551,56^{\star}$ \\
\hline$M G$ & $131,54^{*}$ & $103,29^{*}$ & 156,88 & 87,20 & 520,48 & $741,21^{*}$ \\
\hline SE & $190,04^{*}$ & $97,39^{*}$ & 162,00 & $391,60^{*}$ & 101,20 & 211,21 \\
\hline PB & $229,10^{*}$ & $223,54^{*}$ & $204,78^{*}$ & $277,99^{*}$ & $920,42^{*}$ & $847,57^{\star}$ \\
\hline Constante & 130,89 & 65,42 & $377,87^{\star}$ & $471,17^{\star}$ & $1517,36^{*}$ & $2751,44^{*}$ \\
\hline \multicolumn{7}{|l|}{ Parte Aleatória } \\
\hline sd(_cons) & $229,61^{*}$ & $161,37^{\star}$ & $411,35^{\star}$ & $367,89^{*}$ & $1245,56^{\star}$ & $1034,70^{*}$ \\
\hline sd(Tempo de Programa) & $143,57^{*}$ & $123,70^{*}$ & $214,74^{*}$ & $207,67^{\star}$ & $394,82^{*}$ & $290,68^{*}$ \\
\hline corr(tp, _cons) & $-0,77^{\star}$ & $-0,70^{*}$ & $-0,65^{\star}$ & $-0,48^{*}$ & $-0,74^{*}$ & $-0,56^{*}$ \\
\hline sd(Residual) & $432,21^{*}$ & $409,67^{\star}$ & $709,64^{*}$ & $706,40^{\star}$ & $1164,42^{*}$ & $1073,72^{*}$ \\
\hline Log likelihood & $-75108,23$ & $-170926,68$ & $-35025,69$ & $-53845,47$ & $-17732,49$ & $-18633,03$ \\
\hline
\end{tabular}

Fonte: Elaborada pelos autores com base nos registros administrativos do programa Crediamigo. * Estatisticamente significante ao nível de confiança de 95\%. Variáveis omitidas: Quando for variável binária é o complemento. Demais variáveis omitidas: Analfabeto, Domicílio Próprio, Nenhum Controle Administrativo, Negócio Fixo,Vendas à Vista, Comércio, Prestação 3 meses e unidade de federação Ceará. 